Gut, 1980, 21, 44-48

\title{
Microvillous surface area in secondary disaccharidase deficiency
}

\author{
A D PHILlipS ${ }^{1}$, SARA AVIGAD, JOANNA SACKS, S J RICE, N E FRANCE, \\ AND J A WALKER-SMITH \\ From the Queen Elizabeth Hospital for Children, London
}

SUMMARY Electron microscopy was used to measure microvillous surface area in seven small intestinal biopsies showing secondary disaccharidase deficiency and in five biopsies having normal disaccharidase levels. There were significant reductions in microvillous surface area in the enzyme deficient group, although the microvilli were not severely damaged. Histological abnormality was not always present with disaccharidase deficiency. There was no significant difference in intraepithelial lymphocyte counts between the two groups.

The majority of small intestinal disaccharidases are found in the brush border of the enterocyte (Crane, 1968), and have been shown to be specifically associated with the microvillous membrane (Johnson, 1967; Alpers and Seetharam, 1977). It would seem probable in view of this location that there should be a relationship between the amount of microvillous surface area and the level of disaccharidase activity in a small intestinal mucosal biopsy. Supporting this suggestion is the fact that in coeliac disease there is both a reduction in microvillous height of the mucosal enterocytes (Shiner, 1974), and a reduction in mucosal disaccharidase activity (Anderson, 1966; McNeish and Sweet, 1968).

This study was undertaken firstly to investigate whether the microvillous surface area and disaccharidase activity of the enterocytes of the small intestinal mucosa are interrelated; and secondly to ascertain the appearance of the microvilli in cases of secondary disaccharidase deficiency, as, though it has been widely assumed that the deficiency is due to the temporary damage of the microvilli of the enterocyte, this has not yet been satisfactorily documented.

\section{Methods}

\section{PATIENTS}

We studied 12 biopsies, taken from 10 children who had been admitted to the Queen Elizabeth Hospital for Children for investigation of a variety of gastrointestinal complaints. The clinical details of the

${ }^{1}$ Address for correspondence: $\mathrm{Mr}$ A D Phillips, Electron Microscopist, Department of Histopathology and Cytogenetics, Queen Elizabeth Hospital for Children, Hackney Road, London E2 8PS.

Received for publication 2 August 1979 children are shown in Table 1. Most children were under three years of age, and all were Caucasian, except patient S.P. who was from the Indian subcontinent.

Biopsies were taken, after an overnight fast, under fluoroscopic observation using the double port modification of the paediatric Crosby capsule (Kilby, 1976). The site of biopsy was the fourth part of the duodenum or the duodenojejunal flexure. Each biopsy provided a sample for histological study, disaccharidase assay, and electron microscopy. Histological findings were described as normal (N) or near normal $(+/-)$, or one of three grades of abnormality $(+,++,+++)$ (Harrison et al., 1976).

ESTIMATION OF DISACCHARIDASE ACTIVITY Immediately on removal from the capsule a small piece $(0.5-4.0 \mathrm{mg})$ was cut from the intestinal biopsy, wrapped in about $1 \mathrm{~cm}^{2}$ of tinfoil and frozen in liquid nitrogen. The sample was stored in a $3 \mathrm{ml} \mathrm{screw-}$ capped Sterilin tube at $-60^{\circ} \mathrm{C}$ until estimation of disaccharidase activities could be performed (0-24 days).

On thawing, the piece was briefly dipped in sterile normal saline, blotted dry on filter paper, weighed and homogenised at $0^{\circ} \mathrm{C}$ in 80 volumes of water. This homogenate was used for lactase and sucrase estimations; it was further diluted to 1 in 480 for the maltase estimation. Disaccharidases were estimated by a modification of the method of Dahlqvist (1970), using 4-amino phenazone and phenol in the glucose oxidase step (Trinder, 1969). 20 $\mu$ l of homogenate were incubated at $37^{\circ} \mathrm{C}$ for 40 minutes with $20 \mu$ of $0.056 \mathrm{M}$ lactose, maltose or sucrose in $0.01 \mathrm{M}$ phos- 
Table 1 Clinical details

\begin{tabular}{|c|c|c|c|c|c|c|}
\hline $\begin{array}{l}\text { Biopsy } \\
\text { no. }\end{array}$ & Patient & Sex & $\begin{array}{l}\text { Age } \\
\text { (months) }\end{array}$ & Diagnosis & Biopsy & $\begin{array}{l}\text { Disaccharidases } \\
\text { (normal or reduced) }\end{array}$ \\
\hline $\left.\begin{array}{l}1 \\
2\end{array}\right\}$ & S.T. & $\mathbf{M}$ & 15 & Post enteritis syndrome, CMPI & $\begin{array}{l}\text { Pre milk challenge } \\
\text { Post milk challenge }\end{array}$ & $\begin{array}{l}\mathbf{N} \\
\mathbf{R}\end{array}$ \\
\hline 3 & J.O. & $\mathbf{M}$ & 16 & Multiple food intolerance & Pre milk challenge & $\mathbf{N}$ \\
\hline 4 & S.P. & $\mathbf{F}$ & 20 & CMPI & Pre milk challenge & $\mathbf{N}$ \\
\hline 5 & L.R. & $\mathbf{M}$ & 34 & Chronic diarrhoea & Investigation & $\mathbf{N}$ \\
\hline 6 & M.R. & $\mathbf{M}$ & 168 & Acute inflammatory bowel disease* & Investigation & $\mathbf{N}$ \\
\hline 9 & M.M. & $\mathbf{F}$ & 10 & Irritable colon syndrome & Investigation & $\mathbf{R}$ \\
\hline 10 & S.H. & $\mathbf{F}$ & 12 & Post enteritis syndrome & Investigation & $\mathbf{R}$ \\
\hline 11 & G.S. & $\mathbf{M}$ & 16 & Failure to thrive, ? coeliac & 3 month gluten challenge & $\mathbf{R}$ \\
\hline 12 & L.H. & $\mathbf{M}$ & 20 & Cystic fibrosis, CMPI, ? coeliac & Pre milk challenge & $\mathbf{R}$ \\
\hline
\end{tabular}

CMPI: cow's milk protein intolerance.

*Manuel et al. (1978).

phate buffer, $\mathrm{pH} 6 \cdot 0$. To stop disaccharidase activity and develop glucose colour, $600 \mu \mathrm{l}$ of 'colour reagent' (see appendix) was added to each tube and incubation continued for another $\mathbf{4 0}$ minutes. Suitable homogenate and substrate blanks, a reagent blank, and a standard containing 100 nmol glucose were treated in a similar fashion. After colour development, tubes were centrifuged and the absorbence at $515 \mathrm{~nm}$ was read in $1 \mathrm{~cm}$ cuvettes on a Unicam SP 500 spectrophotometer. Disaccharidase activities were calculated from these results. Control ranges (Table 2) were calculated using the disaccharidase activities from the biopsies of children who had no gastroenterological symptoms at the time of biopsy or whose symptoms were subsequently attributed to non-gastroenterological causes. All of these control specimens came from the fourth part of the duodenum or the duodenojejunal flexure, and were histologically normal.

\section{ELECTRON MICROSCOPY}

The samples for electron microscopy were processed as described previously (Phillips et al., 1979). The surface area of microvilli per square micron of cell surface-that is, the increase in surface area afforded by the microvilli-was also calculated as described earlier (Phillips et al., 1979), with the following modifications: each villus was split into five equal regions (Fig. 1) and a minimum of two microvillous surface area measurements were performed at each

Table 2 Disaccharidase enzyme activities: control data

\begin{tabular}{lllc}
\hline & \multicolumn{2}{c}{ Enzyme } & \\
\cline { 2 - 4 } & Lactase & Maltase & Sucrase \\
\hline Mean activity & $4 \cdot 5$ & $25 \cdot 7$ & $6 \cdot 9$ \\
Mean \pm 2 SD & $1 \cdot 7-11 \cdot 7$ & $13 \cdot 1-50 \cdot 6$ & $3 \cdot 2-14 \cdot 9$ \\
Number of biopsies & 16 & 16 & 15
\end{tabular}

All activities are expressed as $\mu \mathrm{mol}$ substrate cleaved per minute per gram wet weight.

Note: A log normal distribution has been assumed. level for each biopsy, the means being presented in the results; on average, microvilli were measured along $2 \mu \mathrm{m}$ of cell surface for each microvillous surface area calculation; mean microvillous height in the mid villous region of each biopsy was recorded.

Intraepithelial lymphocytes, per 100 epithelial cells, were counted as described by Ferguson et al. (1976).

The biopsies under study were divided into two groups: (1) normal, when the activities of the three disaccharidases were within the normal ranges, and (2) reduced, when one or more of the disaccharidase activities were low.

Student's $t$ test, modified for small numbers, was applied to the results.

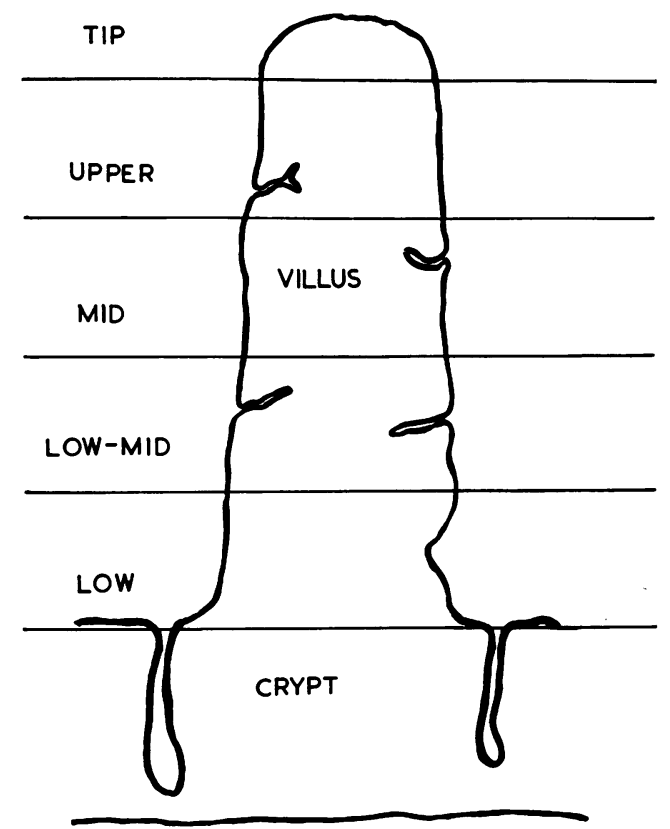

Fig. 1 Diagrammatic representation of the five villous regions. 
Table 3 Patients with normal and with reduced disacharidase enzyme activities: details of histology, cell surface area increase afforded by microvilli, microvillous appearance, and intraepithelial lymphocyte levels

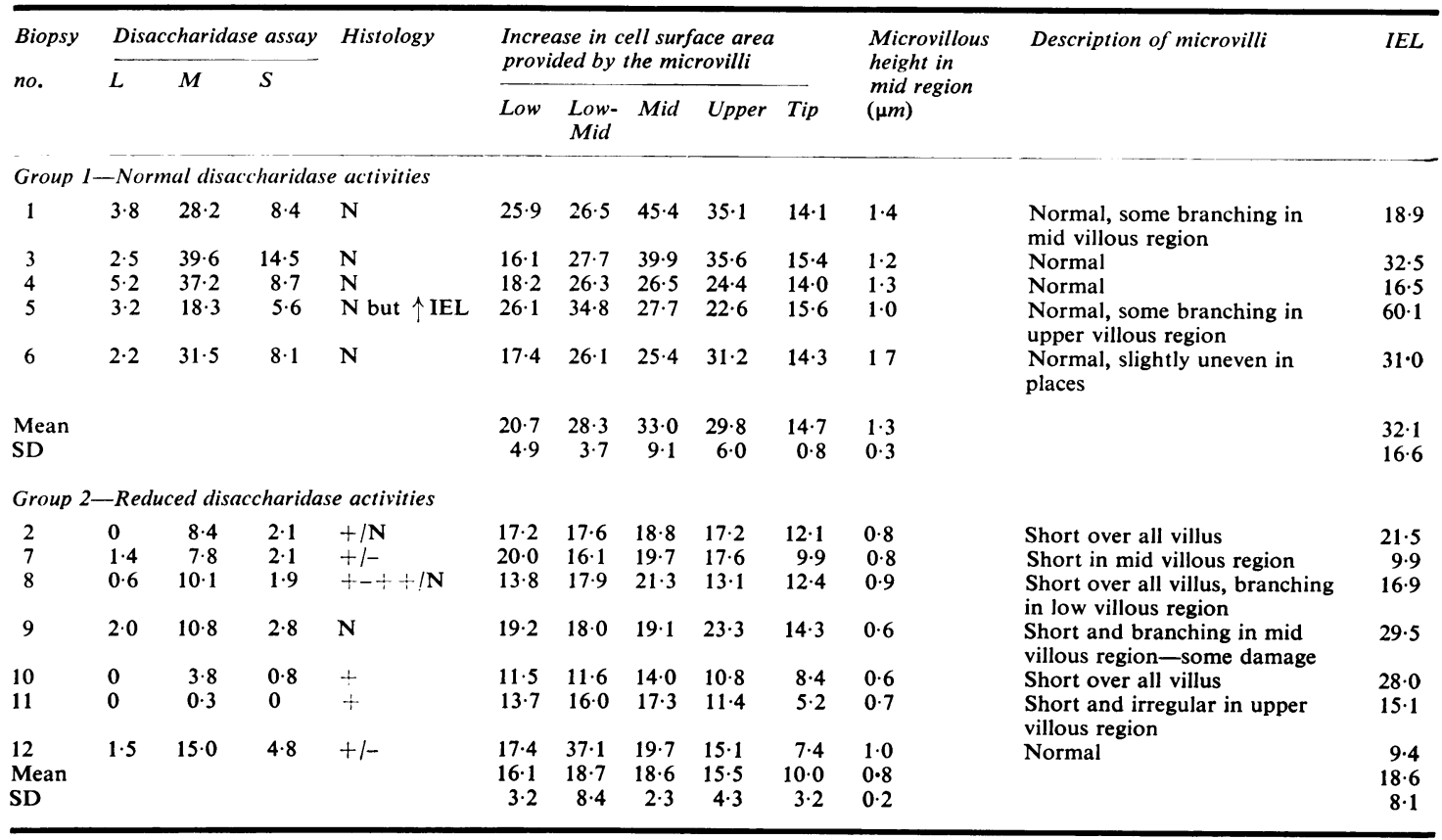

L: lactase. M: maltase. S: sucrase. IEL: intraepithelial lymphocyte count.

\section{Results}

The histological findings, the results of the disaccharidase assay, the increase in surface area afforded by the microvilli, a subjective description of the microvillous appearance, the microvillous height in the mid region, and the intraepithelial lymphocyte count are shown in Table 3.

In the normal disaccharidase group there was a trend for the cell surface area provided by the microvilli to increase from the low to the mid region of the villus, where it reached a maximum, and to decrease from the mid region towards the tip where it reached a minimum, as shown previously (Phillips et al., 1979). In those biopsies where the disaccharidase activity was low, this pattern did not always exist, although the microvillous surface area per square micron of cell surface always decreased towards the
Fig. 2 The mean increase in cell surface area provided by microvilli in the various villous regions from patients with normal disaccharidase activities (hatched line) and patients with reduced disaccharidase activities (solid line). Vertical bars $= \pm$ one standard deviation.

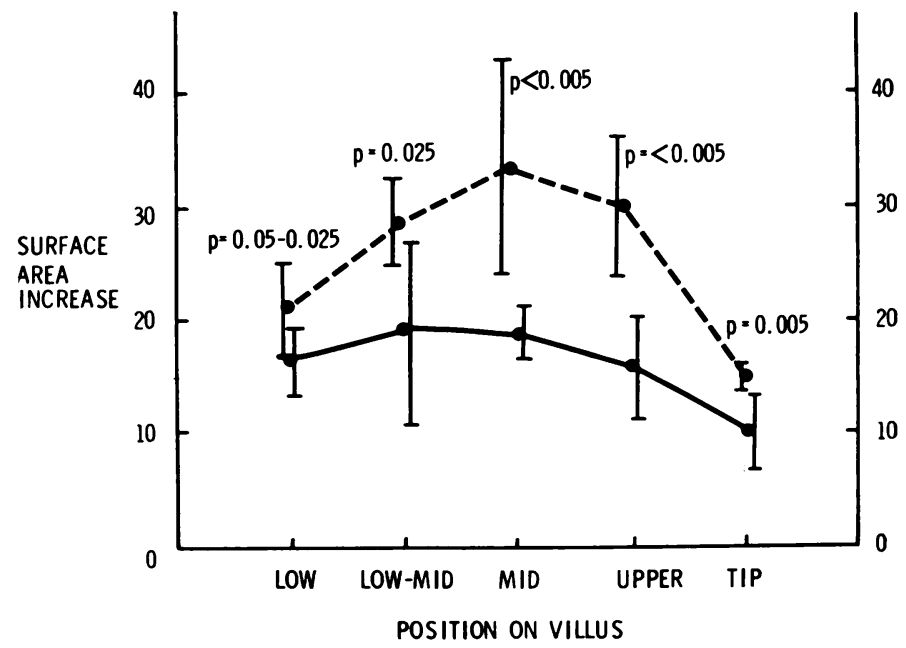




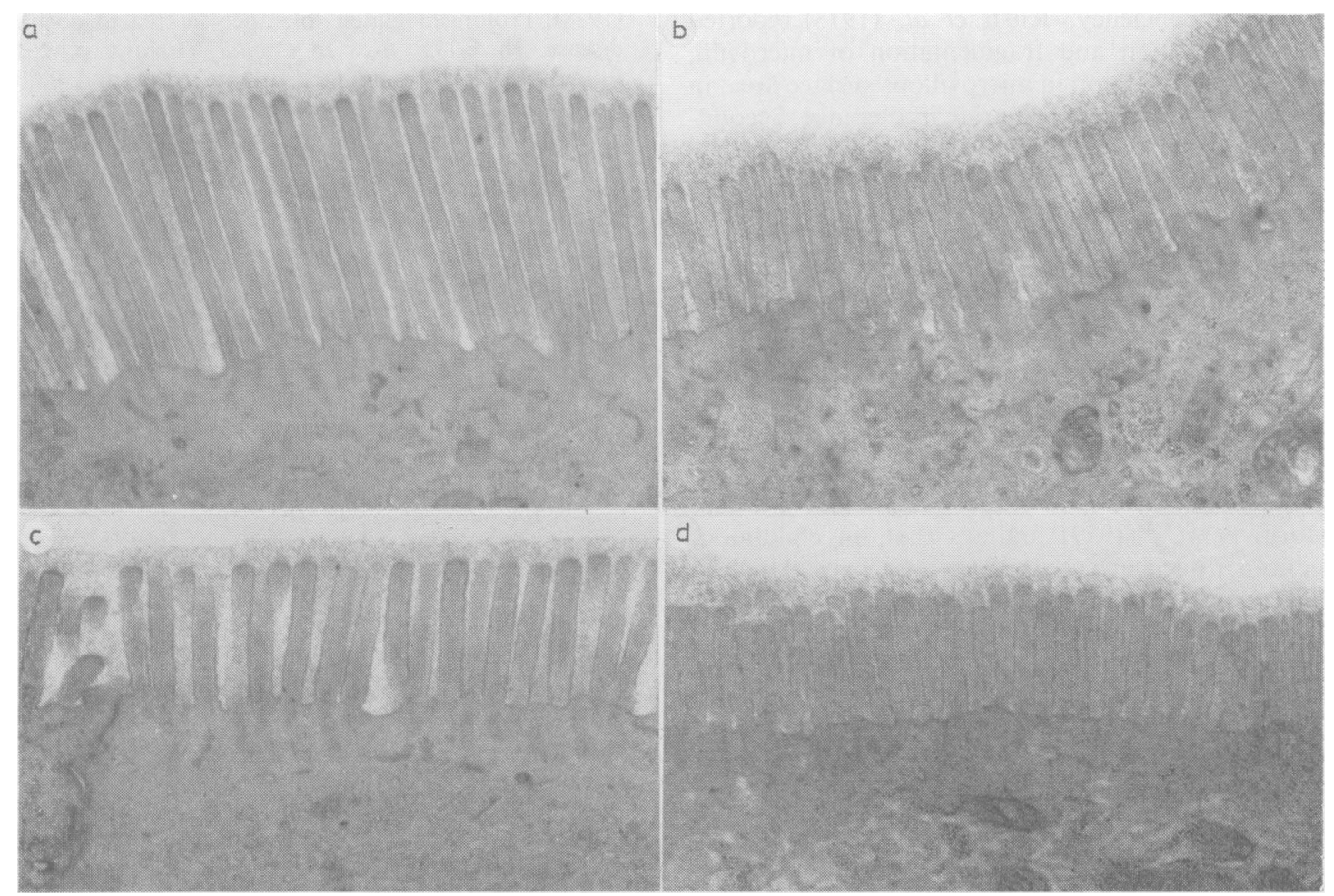

Fig. 3 Microvillous appearances in relation to disaccharidase activity in patient S.T. $(a, c)$ pre-milk challenge (biopsy number 1), microvilli from the mid (a) and tip (c) villous regions. $(b, d)$ post-milk challenge (biopsy number 2), microvilli from the mid (b) and tip (d) villous regions. $\times 30,300$.

tip. Mean microvillous height in the mid region was significantly shorter $(P<0.005)$ in the reduced disaccharidase group.

The mean microvillous surface areas per square micron of cell surface of the two groups were compared at the different villous levels (Fig. 2). The mean microvillous surface areas of the normal disaccharidase group were higher than those of the reduced disaccharidase group at the same villous level. Statistically significant differences (Fig. 2) were found at all levels; the most significant differences were found when comparing the mid and upper villous regions of the two groups $(\mathrm{P}<0.005)$.

An example of the microvillous appearance in biopsies with normal and reduced disaccharidase activities is shown in Fig. 3. The biopsies were from the same child (S.T.) before and after challenge with cow's milk.

The mean intraepithelial lymphocyte count of the normal disaccharidase group was higher than the mean intraepithelial lymphocyte count of the reduced disaccharidase group, although the difference was not statistically significant, being primarily due to a very high count in one of the normal disaccharidase biopsies (L.R.) (Table 3).

\section{Discussion}

In the children we have studied there was an interrelationship between microvillous surface area and disaccharidase activity - that is, when disaccharidase activity was reduced then the microvillous surface area was also reduced. This is consistent with the observation that disaccharidase enzymes are localised on the microvillous membrane (Alpers and Seetharam, 1977). Height is the major contributory factor to the surface area of a microvillus and alterations in this dimension account for most of the changes in surface area. Thus, in the mid region of the villus, the microvilli are shorter in the reduced disaccharidase group and they present less surface area.

The occurrence of a reduction in surface area, rather than generalised microvillous disruption, suggests an alteration in the turnover or synthesis of microvillous membrane, perhaps as a result of a restriction in the supply of necessary metabolites, or a case of demand exceeding supply when turnover of microvillous membrane is high.

In contrast with our findings of limited instances of microvillous degeneration in secondary disac- 
charidase deficiency, Klish et al. (1978) reported severe distortion and fragmentation of microvilli, as well as a reduction in microvillous surface area, in acute acquired monosaccharide intolerance. Secondary monosaccharide intolerance is a more complete manifestation of sugar intolerance than just intolerance to disaccharide, which occurs in the same clinical condition (Anderson and Burke, 1975) and the extent of microvillous damage may determine the extent of carbohydrate intolerance.

Although there was a reduction in microvillous surface area in the disaccharidase deficient group, the histological gradings (Tables 3 and 4) did not show a uniform abnormality-indeed, three of the seven biopsies were normal or near normal. This supports Harrison and Walker-Smith's (1977) and Morin et al.'s (1979) findings that, in childhood, reduced disaccharidase activity and overt mucosal damage are not always related and demonstrates that a normal histology coupled with disaccharidase deficiency is not restricted to primary disaccharidase disorders.

The interrelationship between intraepithelial lymphocyte levels and disaccharidase activities in children with coeliac disease having a gluten challenge has been described by Egan-Mitchell et al. (1978). Although this may be true for coeliac disease, it does not seem to be a general rule, as no statistical difference was found between the normal and reduced disaccharidase groups in this study.

We would like to thank Mrs Faith Byron for her histological assistance. J.S. wishes to thank Dr A. D. Patrick for his help in establishing the disaccharidase assay. We would also like to express our appreciation to the Queen Elizabeth Hospital for Children Research Appeal Trust for their financial assistance for parts of this work.

\section{References}

Alpers, D. H., and Seetharam, B. (1977). Pathophysiology of diseases involving intestinal brush-border proteins. New England Journal of Medicine, 296, 1047-1050.

Anderson, C. M., and Burke, V. (1975). Disorders of carbohydrate digestion and absorption (pp. 199-217). In Paediatric Gastroenterology. Edited by C. M. Anderson and V. Burke. Blackwell: Oxford.

Anderson, Charlotte M., Burke, V., Messer, M., and Kerry, K. R. (1966). Sugar intolerance and coeliac disease (Letter). Lancet, 1, 1322.

Crane, R. K. (1968). Digestion and absorption of carbohydrates. In Carbohydrate Metabolism and its Disorders, vol. 1, pp. 25-51. Edited by F. Dickens, P. J. Randle, and W. J. Whelan. Academic Press: London.

Dahlqvist, A. (1970). Assay of intestinal disaccharidases. Enzymologia Biologica et Clinica, 11, 52-66.

Egan-Mitchell, B., Fottrell, P. F., and McNicholl, B.
(1978). Prolonged gluten tolerance in treated coeliac disease. In Perspectives in Coeliac Disease, p. 251. Edited by B. McNicholl, C. F. McCarthy, and P. F. Fottrell. MTP Press: Lancaster.

Ferguson, A., McClure, J. P., and Townley, R. R. W. (1976). Intraepithelial lymphocyte counts in small intestinal biopsies from children with diarrhoea. Acta Paediatrica Scandinavica, 65, 541-546.

Harrison, B. M., Kilby, A., Walker-Smith, J. A., France, N. E., and Wood, C. B. S. (1976). Cows' milk protein intolerance: a possible association with gastroenteritis, lactose intolerance, and IgA deficiency. British Medical Journal, 1, 1501-1504.

Harrison, M., and Walker-Smith, J. A. (1977). Reinvestigation of lactose intolerant children: lack of correlation between continuing lactose intolerance and small intestinal morphology, disaccharidase activity, and lactose tolerance tests. Gut, 18, 48-52.

Johnson, C. F. (1967). Disaccharidase: localization in hamster intestine brush borders. Science, 155, 16701672 .

Kilby, A. (1976). Paediatric small intestinal biopsy capsule with two ports. Gut, 1\%, 158-159.

Klish, W. J., Udall, J. N., Rodriguez, J. T., Singer, D. B., and Nichols, B. L. (1978). Intestinal surface area in infants with acquired monosaccharide intolerance. Journal of Paediatrics, 92, 566-571.

McNeish, A. S., and Sweet, E. M. (1968). Lactose intolerance in childhood coeliac disease. Assessment of its incidence and importance. Archives of Disease in Childhood, 43, 433-437.

Manuel, P. D., Kilby, A., Candy, D., Walker-Smith, J. A., and Harries, J. T. (1978). Acute inflammatory bowel disease in childhood: a new disease? Archives of Disease in Childhood, 53, 642-644.

Morin, C. L., Buts, J-P., Weber, A., Roy, C. C., and Brochu, P. (1979). One-hour blood-xylose test in diagnosis of cow's milk protein intolerance. Lancet, 1 , 1102-1104.

Phillips, A. D., France, N. E., and Walker-Smith, J. A. (1979). The structure of the enterocyte in relation to its position on the villus in childhood: an electron microscopical study. Histopathology, 3, 117-130.

Shiner, M. (1974). Coeliac disease. Electron microscopy of jejunal mucosa. Clinics in Gastroenterology, 3, 33-53.

Trinder, P. (1969). Determination of glucose in blood using glucose oxidase with an alternative oxygen acceptor. Annals of Clinical Biochemistry, 6, 24-27.

\section{Appendix}

\section{COLOUR REAGENT}

a. $30 \mathrm{mg}$ 4-amino-phenazone; 4500 units horseradish peroxidase (Schwartz Bio-research Inc.) 1500 units glucose oxidase (Sigma Type V); $100 \mathrm{mg}$ sodium azide in $100 \mathrm{ml} 0.5 \mathrm{M}$ Tris buffer $\mathrm{pH} 7 \cdot 2$. Stored at $4^{\circ} \mathrm{C}$.

b. $0 \cdot 1 \%$ phenol in water. Stored in the dark at $4{ }^{\circ} \mathrm{C}$. Mix 3 volumes of (a) with 1 volume (b) just before use. 